\title{
Hubungan Motivasi Kerja dengan Produktivitas Pegawai pada Kantor Setda Kabupaten Bima
}

\author{
M. Riszky Araffah \\ attarismail03@gmail.com \\ Sekolah Tinggi Ilmu Ekonomi (STIE) Bima \\ Ita Purnama \\ ita123purnama@gmail.com \\ Sekolah Tinggi Ilmu Ekonomi (STIE) Bima
}

\begin{abstract}
Abstrak
Tujuan dari penelitian ini adalah untuk mengetahui dan menganalisis hubungan antara motivasi kerja dengan produktivitas kerja pegawai pada Kantor Setda Kabupaten Bima. Teknik analisa data yang digunakan adalah Uji Validitas, Uji Reliabilitas, Analisis Regresi Linear Sederhana, Koefisien Korelasi, Determinasi, dan Uji t. Hasil dari analisa data diperoleh persamaan regresi $Y=19,891+0,607(x)$, persamaan tersebut menunjukkan bahwa, apabila motivasi kerja $=0$ maka produktivitas pegawai sebesar 19,891. Apabila motivasi kerja dinaikkan sebesar 1, maka akan mempengaruhi produktivitas pegawai sebesar 0,607. Korelasi $(r)=0,594$, berarti hubungan antara motivasi kerja dengan produktivitas pegawai sebesar 0,594 dan dikategorikan sebagai korelasi sedang sesuai dengan pedoman untuk memberikan interpretasi koefisien korelasi. Nilai $t_{\text {hitung }}=5,533$ dikomparasikan dengan nilai $t_{\text {tabel }}$ pada taraf kesalahan 5\% untuk uji dua pihak dengan derajat kebebasan ( $\mathrm{dk})=n-2=58-2=56$. Karena pada tabel distribusi t tidak ada nilai $d k 56$, maka dilakukan interpolasi $d k=40$ dan $d k=60(2,021+2,000): 2=2,0105$. Maka hipotesis yang menyatakan bahwa bahwa terdapat hubungan yang signifikan antara motivasi kerja dengan produktivitas pegawai pada Kantor Setda Kabupaten Bima dapat diterima sesuai dengan ketentuan pengujian hipotesis jika $t_{\text {hitung }}$ lebih kecil dari $t_{\text {tabel }}\left(t_{\text {hitung }}<t_{\text {tabel }}\right)$, maka Ho diterima dan $\mathrm{Ha}$ ditolak. Sebaliknya jika $t_{\text {hitung }}$ lebih besar dari $t_{\text {tabel }}\left(t_{\text {hitung }}>t_{\text {tabel }}\right)$, maka Ho ditolak dan $\mathrm{Ha}$ diterima.
\end{abstract}

Kata kunci : motivasi kerja, produktivitas kerja

\section{Pendahuluan}

Sumber daya merupakan aset perusahaan yang paling unik, paling rentan, paling murni dan sukar diperkirakan. Setiap karyawan memiliki seperangkat latar belakang yang berbeda, yang akan mempengaruhi harapan masing-masing dan pada gilirannya akan mempengaruhi dinamika hubungan antara manusia dan organisasi. Salah satu faktor yang dapat mendorong meningkatnya produktivitas sumber daya manusia adalah upaya-upaya meningkatkan motivasi kerja yang memadai, seperti memenuhi kebutuhan baik yang bersifat internal maupun eksternal. Pemberian motivasi kerja eksternal dan internal yang semakin baik dapat mendorong karyawan semakin produktif.

Produktivitas dikatakan tinggi jika prosesnya berlangsung menurut prosedur dan mekanisme yang tepat dan cermat atau yang dinilai terbaik dalam melaksanakan suatu pekerjaan. Kegiatan meningkatkan produktivitas harus dimulai dari upaya menumbuhkan dorongan atau motivasi supaya sukses dalam melaksanakan pekerjaan berdasarkan kesadaran. Namun dari lokasi penelitian ditemukan beberapa masalah yaitu masih terdapat pegawai yang kurang profesional dalam melaksanakan tugasnya, seperti masih adanya pegawai yang datang terlambat pada jam kerja yang telah ditetapkan, bersantai-santai pada saat jam kerja, kurang disiplin dan pulang kerja sebelum waktu yang ditentukan, sehingga hal ini juga penting dalam mempengaruhi produktivitas kerja pegawai pada Setda Kabupaten Bima yang kurang disiplin dan kurang taat pada peraturan yang telah ditetapkan oleh pemerintah. 
Oleh karena itu harus ada kerjasama antara pimpinan dan pegawai untuk menciptakan motivasi kerja pegawai dan dapat meningkatkan produktivitas kerja pegawai di Kantor Setda Kabupaten Bima khususnya pada Bagian Administrasi Pembangunan, sehingga setiap pekerjaan yang diberikan dapat terselesaikan sesuai dengan yang diharapkan.

\section{Tinjauan Pustaka}

\subsection{Motivasi Kerja}

Menurut (Hasibuan, 2014), motivasi adalah suatu faktor yang mendorong seseorang untuk melakukan suatu aktivitas tertentu, oleh karena itu motivasi seringkali diartikan pula sebagai faktor pendorong perilaku seseorang. Faktor-faktor yang penting dalam motivasi kerja terbagi menjadi dua yaitu :

a. Faktor Internal

Faktor internal yang dapat mempengaruhi pemberian motivasi kerja pada seseorang antara lain :

1) Keinginan untuk dapat hidup

2) Keinginan untuk dapat memiliki

3) Keinginan untuk memperoleh penghargaan

4) Keinginan untuk memperoleh pengakuan

5) Keinginan untuk berkuasa

b. Faktor Eksternal

Faktor eksternal dalam memotivasi kerja seseorang yaitu :

1) Kompensasi yang memadai

2) Supervisi yang baik

3) Kondisi Lingkungan Kerja

4) Adanya jaminan pekerjaan

5) Status dan tanggung jawab

6) Peraturan yang fleksibel

Selanjutnya indikator motivasi kerja menurut (Hasibuan, 2014) antara lain : 1) kondisi lingkungan kerja, 2) kompensasi, 3) supervisi, 4) adanya jaminan kerja, 5) status dan tanggung jawab, dan 6) peraturan yang fleksibel.

\subsection{Produktivitas Kerja}

(Sedarmayanti, 2007) mengatakan bahwa produktivitas kerja menunjukkan bahwa produktivitas individu merupakan perbandingan dari efektivitas keluaran (pencapaian unjuk kerja maksimal) dengan efisiensi salah satu masukan (tenaga kerja) yang mencakup kuantitas, kualitas dan waktu tertentu.

Indikator produktivitas pegawai menurut (Hasibuan, 2014) antara lain : 1) kemampuan, 2) meningkatkan hasil yang dicapai, 3) semangat kerja, 4) pengembangan diri, 5) mutu, dan 6) efisiensi.

\subsection{Hubungan Motivasi Kerja Dengan Produktivitas Pegawai}

Menurut (Hasibuan, 2014), motivasi penting karena dengan motivasi ini diharapkan setiap individu karyawan mau bekerja keras dan antusias untuk mencapai produktifitas kerja yang tinggi.

\section{Metode Penelitian}

\subsection{Jenis Penelitian}

Jenis penelitian yang digunakan dalam penelitian ini adalah penelitian asosiatif. Penelitian asosiatif menurut (Sugiyono, 2019) merupakan penelitian yang bertujuan untuk mengetahui hubungan antara dua variabel atau lebih. Penelitian asosiatif ini digunakan untuk mengetahui hubungan antara Motivasi Kerja dengan Produktivitas Pegawai pada Kantor Setda Kabupaten Bima. 


\subsection{Populasi dan Sampel}

Populasi menurut (Sugiyono, 2019) adalah wilayah generalisasi yang terdiri atas obyek/subyek yang mempunyai kualitas dan karakteristik tertentu yang ditetapkan oleh peneliti untuk dipelajari dan kemudian ditarik kesimpulan. Populasi yang digunakan yaitu pegawai pada Bagian Administrasi Pembangunan sebanyak 68 orang yang terdiri dari 58 orang PNS dan Honorer, serta tenaga sukarela sebanyak 10 orang.

Sampel menurut (Sugiyono, 2019) adalah bagian dari jumlah dan karakteristik yang dimiliki oleh populasi tersebut. Bila populasi besar, dan peneliti tidak mungkin mempelajari semua yang ada pada populasi, misalnya karena keterbatasan dana, tenaga dan waktu, maka peneliti dapat menggunakan sampel yang diambil dari populasi itu. Adapun jumlah sampel yang digunakan dalam penelitian yaitu sebanyak 58 orang dengan teknik penentuan sampel yaitu purposive sampling, yaitu teknik pengambilan sampel sumber data dengan pertimbangan tertentu (Sugiyono, 2019).

\subsection{Instrumen Penelitian dan Teknik Pengumpulan Data}

Instrumen penelitian merupakan alat bantu bagi peneliti dalam upaya pengumpulan data penelitian. Adapun instrumen yang digunakan dalam penelitian ini adalah dengan memberikan kuesioner (angket) yang berisi sejumlah pernyataan tertulis kepada responden untuk dijawab dan diberi bobot jawaban dengan menggunakan skala likert. Seperti yang ada pada table di bawah ini.

Tabel 1. Skala Penilaian Instrumen Penelitian

\begin{tabular}{|l|c|c|l|}
\hline Variabel & $\begin{array}{l}\text { Item } \\
\text { Pernyataan }\end{array}$ & Bobot & Keterangan \\
\hline X (Motivasi Kerja) & $1-2$ & 5 & Sangat Setuju \\
\hline 1. Kondisi Lingkungan Kerja & $3-4$ & 4 & Setuju \\
\hline 2. Kompensasi & $5-6$ & 3 & Netral \\
\hline 3. Supervisi & $7-8$ & 2 & Tidak Setuju \\
\hline 4. Adanya Jaminan Kerja & $9-10$ & 1 & Sangat Tidak Setuju \\
\hline 5. Status dan Tanggung Jawab & $11-12$ & & \\
\hline 6. Peraturan Yang Fleksiberl & $1-2$ & 5 & Sangat Setuju \\
\hline Y (Produktivitas Pegawai) & $3-4$ & 4 & Setuju \\
\hline 1. Kemampuan & $5-6$ & 3 & Netral \\
\hline 2. Meningkatkan Hasil Yang Dicapai & $7-8$ & 2 & Tidak Setuju \\
\hline 3. Semangat Kerja & $9-10$ & 1 & Sangat Tidak Setuju \\
\hline 4. Pengembangan Diri & $11-12$ & & \\
\hline 5. Mutu &
\end{tabular}

Untuk memperoleh data atau informasi yang akurat dalam penelitian digunakan metode pengumpulan data dengan cara observasi, wawancara (interview), penyebaran kuesioner (angket), dokumentasi, dan studi pustaka.

\subsection{Teknik Analisa Data}

Teknik analisa data yang digunakan yaitu uji validitas dan reliabilitas, analisis regresi sederhana, koefisien korelasi, determinasi, dan uji t.

a. Uji Validitas

Uji Validitas menurut (Sarwono, 2006) menunjukan derajat ketepatan antara data yang sesungguhnya terjadi pada objek dengan data yang dikumpulkan oleh peneliti. Untuk mencari validitas sebuah item, kita mengkorelasikan skor item dengan total item-item tersebut.

b. Uji Reliabilitas

Uji reliabilitas menurut (Sarwono, 2006) adalah sejauh mana hasil pengukuran dengan menggunakan objek yang sama akan menghasilkan data yang sama. 
c. Analisis Regresi Sederhana

Menurut (Sarwono, 2006), analisis regresi sederhana didasarkan pada hubungan fungsional ataupun kausal satu variabel independen dengan satu variabel dependen.

d. Koefisien Korelasi

Analisis korelasi menurut (Sarwono, 2006) merupakan suatu analisis untuk mengetahui tingkat keeratan hubungan antara 2 variabel, yaitu variabel independen $(\mathrm{X})$ dengan variabel dependen $(\mathrm{Y})$ atau untuk mengetahui kuat atau lemahnya hubungan antara variabel independen dan dependen.

e. Determinasi

Koefisien determinasi $\left(\mathrm{R}^{2}\right)$ pada intinya mengukur seberapa jauh kemampuan model dalam menerangkan variasi variabel dependen.

f. Uji t

Uji t (t-test) melakukan pengujian terhadap koefisien regresi secara parsial, pengujian ini dilakukan untuk mengetahui signifikansi peran secara parsial antara variabel independen terhadap variabel dependen dengan mengasumsikan bahwa variabel independen lain dianggap konstan.

4. Analisis Data Dan Pembahasan

4.1. Uji Validitas

Tabel 2. Hasil Uji Validitas Instrumen Penelitian

\begin{tabular}{|c|c|c|c|c|}
\hline $\begin{array}{c}\text { Variabel } \\
\text { Penelitian }\end{array}$ & Pernyataan & r hitung & r pembanding & Keterangan valid \\
\hline \multirow{8}{*}{$\begin{array}{l}\text { Motivasi } \\
\text { Kerja (X) }\end{array}$} & Item 1 & 0,572 & 0,30 & Valid \\
\hline & Item2 & 0,488 & 0,30 & Valid \\
\hline & Item3 & 0,361 & 0,30 & Valid \\
\hline & Item4 & 0,405 & 0,30 & Valid \\
\hline & Item5 & 0,407 & 0,30 & Valid \\
\hline & Item6 & 0,571 & 0,30 & Valid \\
\hline & Item7 & 0,707 & 0,30 & Valid \\
\hline & Item8 & 0,527 & 0,30 & Valid \\
\hline \multirow{4}{*}{$\begin{array}{l}\text { Motivasi } \\
\text { Kerja (X) }\end{array}$} & Item9 & 0,565 & 0,30 & Valid \\
\hline & Item10 & 0,558 & 0,30 & Valid \\
\hline & Item11 & 0,558 & 0,30 & Valid \\
\hline & Item12 & 0,361 & 0,30 & Valid \\
\hline \multirow{12}{*}{$\begin{array}{c}\text { Produktivita } \\
\text { s Pegawai } \\
\text { (Y) }\end{array}$} & Item 1 & 0,450 & 0,30 & Valid \\
\hline & Item2 & 0,438 & 0,30 & Valid \\
\hline & Item3 & 0,573 & 0,30 & Valid \\
\hline & Item4 & 0,507 & 0,30 & Valid \\
\hline & Item5 & 0,389 & 0,30 & Valid \\
\hline & Item6 & 0,470 & 0,30 & Valid \\
\hline & Item7 & 0,691 & 0,30 & Valid \\
\hline & Item8 & 0,330 & 0,30 & Valid \\
\hline & Item9 & 0,378 & 0,30 & Valid \\
\hline & Item 10 & 0,417 & 0,30 & Valid \\
\hline & Item11 & 0,450 & 0,30 & Valid \\
\hline & Item12 & 0,573 & 0,30 & Valid \\
\hline
\end{tabular}

Sumber : Data yang dioleh

Berdasarkan tabel pengujian validitas di atas, semua item pernyataan pada variabel motivasi kerja dan produktivitas pegawai dinyatakan valid, karena $r$ hitung $>r$ pembanding. 


\subsection{Uji Reliabilitas}

Tabel 3. Hasil Uji Reliabilitas Variabel X

\begin{tabular}{|c|c|c|}
\hline \multicolumn{3}{|c|}{ Reliability Statistics } \\
\hline & $\begin{array}{c}\text { Cronbach's } \\
\text { Cronbach's } \\
\text { Alpha Based on } \\
\text { Standardized } \\
\text { Items }\end{array}$ & N of Items \\
\hline .723 & .742 & 12 \\
\hline
\end{tabular}

Tabel 4. Hasil Uji Reliabilitas Variabel Y

\begin{tabular}{|c|c|c|}
\hline \multicolumn{3}{|c|}{ Reliability Statistics } \\
\hline $\begin{array}{c}\text { Cronbach's } \\
\text { Alpha }\end{array}$ & $\begin{array}{c}\text { Cronbach's } \\
\text { Alpha Based on } \\
\text { Standardized } \\
\text { Items }\end{array}$ & \\
\hline .695 & N of Items \\
\hline
\end{tabular}

Hasil penelitian antara variabel X dan Y menggambarkan nilai cronbach's alpha $>0,60$. Sehingga pernyataan kuisioner dapat dikatakan reliabel.

\subsection{Regresi Sederhana}

Tabel 5. Hasil Analisis Regresi Sederhana

\begin{tabular}{|c|c|c|c|c|c|c|}
\hline \multicolumn{7}{|c|}{ Coefficients $^{a}$} \\
\hline & & \multicolumn{2}{|c|}{ Unstandardized Coefficients } & $\begin{array}{c}\text { Standardized } \\
\text { Coefficients }\end{array}$ & \multirow[b]{2}{*}{$\mathrm{t}$} & \multirow[b]{2}{*}{ Sig. } \\
\hline \multicolumn{2}{|c|}{ Model } & $\mathrm{B}$ & Std. Error & Beta & & \\
\hline \multirow[t]{2}{*}{1} & (Constant) & 19.891 & 5.491 & & 3.622 & .001 \\
\hline & motivasi kerja & .607 & .110 & .594 & 5.533 & .000 \\
\hline
\end{tabular}

Berdasarkan nilai signifikansi dari tabel coefficients di atas diperoleh nilai signifikansi sebesar $0,000<0,05$, sehingga dapat disimpulkan bahwa variabel motivasi kerja $(X)$ memiliki hubungan signifikan dengan variabel produktivitas pegawai (Y).

\subsection{Koefisien Korelasi}

Tabel 6. Hasil Uji Koefisien Korelasi

\begin{tabular}{|c|c|c|c|c|c|c|c|c|c|}
\hline \multicolumn{10}{|c|}{ Model Summary } \\
\hline \multirow[b]{2}{*}{ Model } & \multirow[b]{2}{*}{$\mathrm{R}$} & \multirow[b]{2}{*}{ R Square } & \multirow[b]{2}{*}{$\begin{array}{l}\text { Adjusted } \\
\text { R Square }\end{array}$} & \multirow{2}{*}{$\begin{array}{l}\text { Std. Error } \\
\text { of the } \\
\text { Estimate }\end{array}$} & \multicolumn{5}{|c|}{ Change Statistics } \\
\hline & & & & & $\begin{array}{l}\text { R Square } \\
\text { Change }\end{array}$ & $\begin{array}{c}\mathrm{F} \\
\text { Change }\end{array}$ & df1 & df2 & $\begin{array}{c}\text { Sig. F } \\
\text { Change }\end{array}$ \\
\hline 1 & $.594^{\mathrm{a}}$ & .353 & .342 & 3.929 & .353 & 30.611 & 1 & 56 & .000 \\
\hline
\end{tabular}

Berdasarkan tabel di atas diperoleh nilai korelasi (R) sebesar 0,594. Hal ini menunjukkan hubungan antara variabel motivasi kerja dengan produktivitas pegawai hubungan sedang sesuai dengan tabel pedoman interval koefisien korelasi (Sugiyono : 2009)

Tabel 7. Pedoman Interpretasi Koefisien Korelasi

\begin{tabular}{|c|c|}
\hline Interval Koefisien & Tingkat Hubungan \\
\hline \hline $0,00-0,199$ & Sangat Rendah \\
\hline $0,20-0,399$ & Rendah \\
\hline $0,40-0,599$ & Sedang \\
\hline $0,60-0,799$ & Kuat \\
\hline $0,80-1,000$ & Sangat Kuat \\
\hline
\end{tabular}




\subsection{Koefesien Determinasi}

Tabel 8. Hasil Uji Koefesien Determinasi

\begin{tabular}{|c|c|c|c|c|c|c|c|c|c|}
\hline \multicolumn{10}{|c|}{ Model Summary } \\
\hline \multirow[b]{2}{*}{ Model } & \multirow[b]{2}{*}{$\mathrm{R}$} & \multirow[b]{2}{*}{ R Square } & \multirow[b]{2}{*}{$\begin{array}{l}\text { Adjusted } \\
\text { R Square }\end{array}$} & \multirow{2}{*}{$\begin{array}{l}\text { Std. Error } \\
\text { of the } \\
\text { Estimate }\end{array}$} & \multicolumn{5}{|c|}{ Change Statistics } \\
\hline & & & & & $\begin{array}{l}\text { R Square } \\
\text { Change }\end{array}$ & $\begin{array}{c}\mathrm{F} \\
\text { Change }\end{array}$ & df1 & df2 & $\begin{array}{c}\text { Sig. F } \\
\text { Change }\end{array}$ \\
\hline 1 & $.594^{\mathrm{a}}$ & .353 & .342 & 3.929 & .353 & 30.611 & 1 & 56 & .000 \\
\hline
\end{tabular}

Berdasarkan tabel di atas diperoleh nilai determinasi (R Square) sebesar 0,353. Hal ini menunjukkan bahwa variabel motivasi kerja hanya mempengaruhi sebesar 35,3\% terhadap produktivitas pegawai, sedangkan sisanya sebesar $64,7 \%$ dipengaruhi oleh variabel lain yang tidak diteliti dalam penelitian ini.

\subsection{Uji t}

Tabel 9. Hasil Uji t

\begin{tabular}{|c|c|c|c|c|c|c|}
\hline \multicolumn{7}{|c|}{ Coefficients $^{\mathrm{a}}$} \\
\hline \multirow{2}{*}{\multicolumn{2}{|c|}{ Model }} & \multicolumn{2}{|c|}{ Unstandardized Coefficients } & \multirow{2}{*}{$\begin{array}{c}\begin{array}{c}\text { Standardized } \\
\text { Coefficients }\end{array} \\
\text { Beta }\end{array}$} & \multirow[b]{2}{*}{$\mathrm{t}$} & \multirow[b]{2}{*}{ Sig. } \\
\hline & & B & Std. Error & & & \\
\hline \multirow[t]{2}{*}{1} & (Constant) & 19.891 & 5.491 & & 3.622 & .001 \\
\hline & motivasi kerja & .607 & .110 & .594 & 5.533 & .000 \\
\hline
\end{tabular}

Dari hasil uji t pada tabel di atas, diperoleh nilai t hitung sebesar 5,533. Selanjutnya nilai t hitung tersebut dikomparasikan dengan nilai $t$ tabel pada taraf kesalahan $5 \%$ untuk uji dua pihak dengan derajat kebebasan $(\mathrm{dk})=\mathrm{n}-2=58-2=56$. Karena dalam tabel distribusi $\mathrm{t}$, nilai $\mathrm{t}$ yang ada adalah untuk dk 40 dengan nilai 2,021 dan dk 60 dengan nilai 2,000, sedangkan untuk $\mathrm{dk} 56$ tidak ada maka dilakukan interpolasi $\mathrm{dk}=40 \mathrm{dan} \mathrm{dk}=60(2,021+2,000): 2=2,0105$, sehingga disimpulkan nilai t tabel $=2,0105$ (berdasarkan tabel distribusi t Sugiyono, 2009). Sesuai dengan perbandingan antara $t$ hitung dengan $t$ tabel diketahui bahwa nilai $t$ hitung lebih besar dari nilai t tabel atau 5,533 lebih besar dari 2,0105 dengan ketentuan pengujian hipotesis jika $t$ hitung lebih kecil dari $t$ tabel ( $t$ hitung < tabel), maka Ho diterima dan Ha ditolak. Sebaliknya jika $t$ hitung lebih besar dari $t$ tabel ( $t$ hitung $>t$ tabel), maka Ho ditolak dan Ha diterima.

Sesuai hasil tersebut, maka hipotesis yang menyatakan bahwa terdapat hubungan yang signifikan antara motivasi kerja dengan produktivitas pegawai dapat diterima.

\section{Kesimpulan Dan Rekomendasi}

\subsection{Kesimpulan}

Berdasarkan hasil analisis dan pengujian hipotesis, maka dapat ditarik suatu kesimpulan dalam penelitian ini yaitu terdapat hubungan yang signifikan antara motivasi kerja dengan produktivitas pegawai pada Kantor Setda Kab.Bima. Dengan tingkat keeratan hubungan sedang yaitu sebesar 0,594

\section{2. $\quad$ Rekomendasi}

Adapun rekomendasi yang ingin disampaikan berdasarkan hasil penelitian yaitu diharapkan kepada Bapak Pimpinan Kantor Setda Kab. Bima agar tetap memberikan motivasi kepada para pegawai yang ada di bawah naungannya setiap saat, agar dapat lebih meningkatkan produktivitas pegawai. 


\section{Daftar Pustaka}

Hasibuan, M. S. P. (2014). Organisasi \& Motivasi : Dasar Peningkatan Produktivitas (Cetakan 8). Jakarta: Bumi Aksara.

Sarwono, J. (2006). Metode Penelitan Kuntitatif dan Kualitatif. Yogyakarta: Graha Ilmu. Sedarmayanti. (2007). Manajemen Sumber Daya Manusia. Bandung: Refika Aditama.

Sugiyono. (2019). Metode Penelitian Kuantitatif, Kualitatif dan R \& D. Bandung: Alfabeta. 
